\title{
A COLETA DA ERVA-MATE PELA POPULAÇÃO CABOCLA DO VALE DO RIO DO PEIXE E OESTE DE SANTA CATARINA: APROPRIAÇÃO PRIVADA DA TERRA E RUPTURAS (DÉCADAS DE 1900 A 1940)
}

\section{The harvest of erva mate (ilex paraguariensis) by caboclo population in West and Peixe valley river of Santa Catarina States (Brazil): Breaks with the advancement of private appropriation (decades 1900 to 1940)}

\author{
Marlon Brandt \\ Universidade Federal da Fronteira Sul, Chapecó, Santa Catarina, Brasil \\ marlonbrandt@yahoo.com.br \\ Naiara Sampaio Silva \\ Universidade Federal da Fronteira Sul, Chapecó, Santa Catarina, Brasil \\ naiara.2872@gmail.com
}

Artigo recebido em 23/08/2013 e aceito para publicação em 18/07/2014

RESUMO: O presente artigo tem por objetivo analisar a coleta da erva-mate (Ilex paraguariensis) pela população cabocla nas florestas do Vale do Rio do Peixe e Oeste de Santa Catarina, e o processo de apropriação privada da terra e ruptura nessa prática, que se torna mais intenso a partir da década da Primeira República. Nessa região se estabeleceu, desde as primeiras décadas do século XIX, uma significativa parcela de famílias caboclas, na maioria sob o regime da posse, às margens dos latifúndios pastoris localizados nas áreas de campos naturais. Sua fonte de renda básica era ligada à práticas relacionadas à exploração de recursos da floresta, como a extração da erva-mate. Isso foi se desestruturando à medida que uma nova dinâmica sócio-espacial ligada à economia capitalista, representada pela propriedade privada da terra, com a posterior colonização, o cercamento das terras e a exploração madeireira passaram a se fazer presentes na região, principalmente a partir das primeiras três décadas do século XX.

Palavras-chave: Erva-mate; caboclos, apropriação privada da terra.

ABSTRACT: The article aims to analyze the extraction of erva-mate (Ilex paraguariensis) by caboclo populations in the Western forests of Santa Catarina State, the private land appropriation processes and the disarticulation of the extractive practice of the private land appropriation processes, which becomes more intense from the First Republic decades on. In this region, a significant part of caboclo families was settled since the first decades of the nineteenth century, mostly under the ownership regime, next to the pastoral land property located in the areas of natural grassland. The primary source of income was linked to subsistence agriculture and practices related to the exploitation of forest resources, such as the extraction of erva-mate. The disintegration happens when a new social-spatial dynamics becomes present, inducing the private land appropriation, with the subsequent colonization, the fencing of land and the logging.

Keywords: Erva-mate, caboclos, private land appropriation. 
O presente artigo tem por objetivo analisar a extração da erva-mate (Ilex paraguariensis) pela população cabocla nas florestas do Vale do Rio do Peixe e Oeste de Santa Catarina e a desarticulação espacial dessa prática a partir do avanço da apropriação privada da terra, que se torna mais intensa a partir da Primeira República. No presente trabalho utilizamos a definição de população cabocla adotada por Paulo Pinheiro Machado (2004, p. 48), que os descreve como "[...] os habitantes do planalto, ou seja, o habitante pobre do meio rural". Embora, conforme o autor, "não haja uma conotação étnica nesta palavra, frequentemente o caboclo era mestiço, muitas vezes negro". Mas a principal característica desse conceito é que denota uma condição social e cultural, sendo os caboclos homens pobres que se dedicavam a agricultura, criação ou extrativismo, vivendo como sitiantes independentes nos interstícios das grandes fazendas pastoris, na maioria das vezes sendo posseiros, ou agregados ou peões. Para compreender a complexidade desse processo de transformações promovidas pela inserção de uma nova dinâmica sócio-espacial ligada à economia capitalista, parte-se da ideia da indissociabilidade do espaço e do tempo, trabalhando com os preceitos da geografia histórica, pois para se analisar o espaço geográfico, não basta, nas palavras de Maurício de Almeida Abreu 1997, p. 240), "desvendar as suas múltiplas dimensões atuais. Há de se investigar também o processo histórico que lhe deu origem". Se hoje essa região é fortemente marcada pela presença do setor agroindustrial e de pequenos produtores rurais, sua formação está intimamente ligada ao processo de apropriação e concentração da terra, promovida com a articulação do poder estatal e seu fomento à colonização, deixando de lado desse processo inúmeras famílias que já habitavam esses espaços.

Apoiando-se nas ideias de Chris Philo (1996, p. 270-274), para quem, “[...] a complexa geografia do mundo está estreitamente ligada com o que acontece em sua história", procura-se evidenciar nesse enfoque geográfico do passado, não apenas os fenômenos de materialidade óbvia, mas também os fenômenos de natureza "imaterial" na pesquisa geográfica, levando em consideração "[...] todo um conjunto de acontecimentos passageiros (guerras, fomes), entidades abstratas [como as representações sociais, os costumes, a religiosidade] e estruturas mais pro- fundas". Longe se restringir a meras descrições de formas ou paisagens no passado, o que se procura, como destaca Paul Claval (2004, p. 71), é compreender "[...] as relações complexas que se estabelecem entre os indivíduos e os grupos, o ambiente que eles transformam, as identidades que ali nascem ou se desenvolvem".

A erva-mate, planta cuja ocorrência é endêmica, distribui-se na forma silvestre no bioma da Mata Atlântica, principalmente nos Estados de Santa Catarina, Paraná, Rio Grande do Sul e Mato Grosso do Sul, apresentando ocorrências em áreas de maior altitude em São Paulo, Minas Gerais e Rio de Janeiro. A espécie atinge também a província de Misiones, na Argentina, e o leste do Paraguai, compreendendo uma área de 540 mil quilômetros quadrados, sendo 450 mil no Brasil, como pode ser observado na Figura 1. (ANDRADE, 2003; GERHARDT, 2013). 
Figura1: Distribuição da erva-mate (Ilex paraguariensis)

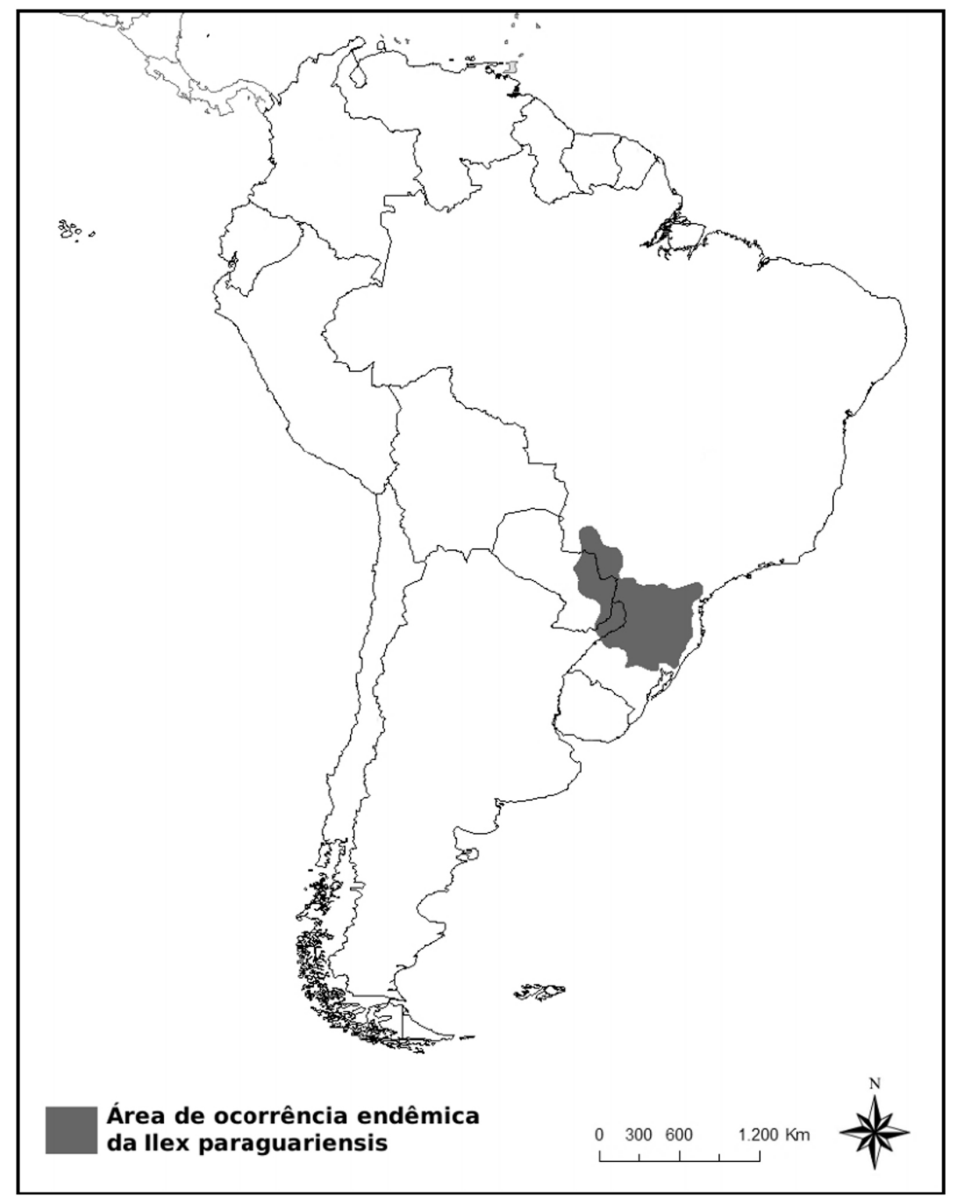

Fonte: Gerhardt, 2013.

O hábito de se consumir a erva-mate através da infusão de suas folhas trituradas em água quente ou fria, era comum desde que essa região era habitada por diversos grupos indígenas sendo bebida individualmente ou em grupo. Herdaram tal tradição os jesuítas através do contato com os indígenas, da mesma forma que paulistas e portugueses que povoaram a região dos Campos de Curitiba ao Rio Grande do Sul, e os espanhóis do Prata, disseminando o hábito de consumo por toda a região platina (QUEIROZ, 1981; GERHARDT, 2013).

A difusão do consumo da bebida nas regiões platinas, onde a planta não possuía ocorrência natural, estimulou o comércio da folha. Inicialmente o Paraguai era o principal fornecedor para os países platinos, porém desde as primeiras décadas do século XIX já havia a comercialização das plantas encontradas em solo brasileiro, sobretudo na região de Curitiba.
Viajantes que percorreram a região de Curitiba nesse período relataram a difusão do hábito de se consumir a infusão das folhas da ilex no Paraná, Rio Grande do Sul, Santa Catarina e São Paulo, e sugeriram que tal atividade poderia assumir o papel de um importante produto comercial. O Padre Manuel Aires de Casal (2010, p. 109), ao percorrer a região de Curitiba no ano de 1817, fez o seguinte comentário sobre a erva-mate em sua descrição da paisagem rural curitibana: “[...] as árvores do mate criam-se espontaneamente, e são mui comuns. O grande uso, que desta bebida se faz na província, e nas de Santa Catarina e Rio Grande, e já adotado por muita gente na metrópole, augura ao país outro ramo de comercio". Apenas três anos depois Saint-Hillaire (1978, p. 88-90) já enfatizava que o produto constituía "um importante produto de exportação para a cidade de Curitiba". A instituição, pelo governo paraguaio, até então principal fornecedor 
da erva-mate a Argentina e o Uruguai, do monopólio estatal na produção do mate, impondo preços aos comerciantes platinos, fez com que esses procurassem no Brasil o produto com condições melhores ou iguais de lucro (QUEIROZ, 1981).

A dualidade campo/floresta nas áreas de ocorrência da planta na porção brasileira marcou a natureza do povoamento europeu de toda a região, tendo seus efeitos sentidos até os dias atuais. Ocupada durante séculos por populações indígenas, a região passou a ser alvo das primeiras incursões européias já no século XVI. Porém, foi com a abertura dos primeiros caminhos de tropas ligando o Rio Grande do Sul ao Sudeste no século XVIII, percorrendo as regiões do planalto, acompanhada da formação de imensas fazendas de criação nas áreas de Campos que a região passou a ser ocupada de modo mais intenso e se inseriu de modo marginal, à economia colonial, como fornecedora de animais e alimentos às regiões mineradoras (BRANDT, 2012).

Nesse contexto, a floresta representava um espaço marginal para a economia predominante, impedindo a maior extensão dos campos e, portanto, de pasto para o gado. Tal situação fez com que a floresta surgisse como uma possibilidade de uma nova vida para muitas pessoas ligadas às atividades pastoris, contribuindo, nas palavras de Paulo Pinheiro Machado $(2004$, p. 355$)$, "para a maior presença social de posseiros e sitiantes independentes". A posse surgiu como uma forma extralegal de acesso à terra ainda no período colonial, quando o acesso oficial a estas ocorria a partir da concessão de sesmarias. De acordo com Emília Viotti da Costa (1999, p. 175) "todas as pessoas que penetravam nas regiões do interior - áreas sem nenhum valor comercial - podiam controlar um pedaço de terra, desde que fossem capazes de enfrentar os índios e sobreviverem na selva". Dessa maneira, "a disponibilidade de grandes extensões de terra tornou-a acessível àqueles que não tinham condições de participar da economia comercial, permitindo-lhes sobreviver no âmbito da economia de subsistência" (COSTA, 1999, p. 175). Ao se instalar nas novas terras, esses moradores poderiam viver do extrativismo da erva-mate onde ela se encontrava com mais abundância, da criação de animais à solta, compartilhando o espaço em comum com moradores vizinhos, da caça, da pesca e da agricultura de subsistência (BRANDT; NODARI, 2011).

Nesse espaço, se os Campos, nas palavras de Maurício Vinhas de Queiroz (1981, p. 32), "marcam as superfícies por onde se estendeu a frente pastoril, os trechos de floresta indicam aquelas por onde se espalhou a atividade extrativa". Como agentes desta expansão espacial, encontravam-se ex-escravos, negros libertos, foragidos da justiça, ex-agregados, peões e fazendeiros em buscas de novas terras, partindo principalmente das áreas situadas, ao leste, nos campos de Lages, Curitibanos e Campos Novos, enquanto do noroeste e oeste partiam dos campos de Guarapuava e de Palmas no Paraná (MACHADO, 2004). No Oeste catarinense, onde a extração da planta em caráter comercial já era destacada no final do século XIX, por Sebastião Paraná (1899), os ervais teriam atraído não apenas esses moradores de origem brasileira, mas também famílias provenientes da Argentina e do Paraguai (CORRÊA, 1970).

Essas famílias ao encontrar uma área onde tal árvore abundava, nela se instalavam e iniciavam a produção, que até meados do século XX, seguia o antigo modelo indígena, extremamente trabalhoso, normalmente nos meses de inverno. Após o corte dos galhos da planta, o trabalho prosseguia no sapeco, na secagem, no quebramento, na peneiração e no ensaque. $\mathrm{O}$ sapeco consiste em uma rápida tostagem da planta no fogo, feito em muitos casos, em pleno local de colheita. Após o sapeco, a erva era então conduzida a secagem. Existiam duas formas de secagem: o carijo e o barbaquá. O primeiro consistia em uma espécie de estrado, feito de varas e cipó, os quais se colocavam as folhas, que deveriam secar durante 10 dias sobre um braseiro. O barbaquá, de elaboração mais complexa, exigindo maior investimento por parte do ervateiro, passou a ser utilizado, sobretudo a partir do século $X X$. Nesse sistema as folhas não secavam diretamente sobre o fogo e o braseiro. O calor era levado até as folhas através de um túnel de alvenaria, que desviava a fumaça, impedindo que essa desse gosto e cheiro a folha, o que ocorria principalmente quando a secagem no carijo era feita incorretamente. Depois de secas, as folhas eram quebradas ou cancheadas, separando folhas, reduzindo-as a pedaços miúdos e a pó. Inicialmente feitos com facões de pau ou no pilão, 
foram, em alguns casos, substituídos pelo trabalho animal, onde um burro ou cavalo conduzia um rolo denteado sobre os galhos secos em uma máquina que se assemelha aos antigos moedores de cana. Também existiam cancheadores que aproveitavam a força hidráulica. Depois de pronto, o produto era acondicionado em bolsas confeccionadas com taquara trançada, bruacas de couro ou barricas, sendo então transportadas em tropa de mulas (QUEIROZ, 1981).

Não existiam, conforme aponta Vinhas de Queiroz (1981), regras muito fixas nas relações entre os homens no trabalho dos ervais. Todo o trabalho, no caso dos sitiantes independentes, dependia somente da força familiar. Esta forma de extração do mate ocorria com maior freqüência em pequenas propriedades ou posses afastadas em plena floresta. Em muitos casos o acesso e uso dos ervais poderia ser em comum, como sugere, por exemplo, o depoimento de Rita Fernandes da Silva, antiga moradora de Chapecó: "assim a erva mate, também não era dizer eu vou lá, a erva, como ali no Bormann você podia ir em qualquer lugar e cortar erva ninguém fazia conta, ninguém fazia conta de você derrubar e tiram um carijo de erva, ninguém se importava" (SILVA, 2006). É o que também expõe David Marsango, antigo morador da região de Ponte Serrada, cuja família mudou-se para a região, dedicando-se às atividades ervateiras: "na época a erva-mate existia em toda a parte, assim silvestre, eles faziam o dia, entravam nestes matos ali, criavam um porquinho [...], tiravam erva, sapecavam ali, ajeitavam ali [e] carregam nos cargueiros" (MARSANGO, 1996).

Moradores locais também poderiam ser empregados ou trabalhar como tarefeiros na coleta da erva-mate para diversas empresas ervateiras, tanto do Brasil quanto em empresas argentinas que possuíam terras no território brasileiro. $\mathrm{O}$ aporte dessas empresas na região fronteiriça atraiu elementos dos três países na atividade ervateira, trabalhando como assalariados nessas companhias. As condições de trabalho nessas empresas eram precárias. Conforme Maristela Ferrari (2011, p. 151), os trabalhadores eram

\section{[...] submetidos a um regime de trabalho semi-escravo, já que muitos ervateiros for- neciam apenas alimentos e ferramentas de trabalho em troca do trabalho deles. [...]}

nos ervais nativos dessa zona fronteiriça [...] os assassinatos de trabalhadores do corte da erva-mate eram, segundo pesquisa de campo, frequentes, como a Mateauda, apontada como uma das empresas que frequentemente cometia assassinatos de trabalhadores nos seus ervais.

A exploração ervateira na região, realizada tanto por sitiantes independentes quanto por companhias ervateiras, seria um dos fatores que contribuíram para o assentamento mais efetivo da população na região, principalmente na fronteira com a Argentina, então principal mercado consumidor. Desse fluxo surgiram núcleos de povoamento como Dionísio Cerqueira, em Santa Catarina, Barracão e Santo Antônio do Sudeste no Paraná, ainda em fins do século XIX (FERRARI, 2011).

A erva-mate seria inclusive moeda corrente entre a população cabocla que permanecia na condição de sitiante independente, cuja produção era vendida a essas companhias. As folhas da erva-mate, após a colheita e o sapeco, eram vendidas a comerciantes locais, muitos deles argentinos - alguns dos quais também ervateiros - na base da troca, por gêneros alimentícios e outros produtos de consumo não produzidos nas suas terras como tecidos, sal açúcar, café, pólvora, dentre outros. Depois, a erva, que poderia ser beneficiada, era destinada a empresas argentinas localizadas na fronteira, a empresas e comerciantes locais ou filiais de ervateiras paranaenses localizadas na região de Porto União. De lá o produto poderia seguir, via férrea, aos portos do Paraná e Santa Catarina (PARANÁ, 1899; CORRÊA, 1970; GOULARTI FILHO, 2012)

A implementação, na primeira década do século XX, da Ferrovia São Paulo-Rio Grande, cujo traçado seguia o rumo do rio do Peixe, dinamizou a produção ervateira nas áreas próximas, atraindo ervateiros interessados em explorar as terras, e comerciantes que despachavam o produto, tendo como destino os países do Prata e o Rio Grande do Sul. O anúncio veiculado na imprensa local na década de 1930, que consta na Figura 2, por exemplo, ilustra a atuação de muitos desses comerciantes, que adquiriam dos produtores da região a erva-mate barbaquá, ou seja, erva-mate já beneficiada por ervateiros locais. A 
extração do produto para posterior venda para esses ervateiros, proprietários dos barbaquás, poderia ser realizada por diversas famílias caboclas que viviam na região. Mesmo que, como veremos adiante, a colonização se fizesse presente de forma intensa na região durante esse período, é possível que em áreas mais afastadas a presença de famílias caboclas que viviam no regime da posse ainda ocorresse, podendo também usufruir a floresta em comum.

Figura 2: Anúncio de compra de erva-mate barbaquá.

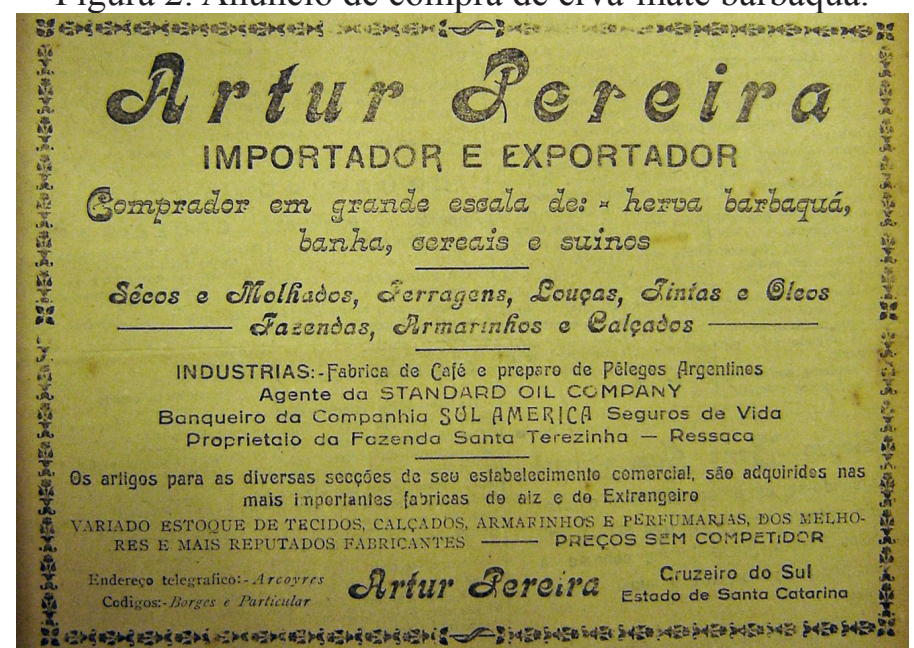

Fonte: O Cruzeiro, 1934.

Davi Marsango menciona a atuação de um desses ervateiros, que chegou a recrutar trabalhadores do Paraguai para a extração da erva-mate na região de Joaçaba

Ele entrava nesse sertão, assim ajeitando, arrumando pra comprá a erva-mate, isto foi depois que abriram a estrada de ferro, aqui em Joaçaba, isso foi por 1908, 1909 por ai,, esse foi o lugar mais perto pra escoar essa dita erva-mate desses fundão, desse município de Palmas, essa região aqui, por esses lados aqui se não antes de explorar essa estrada, aqui pra Joaçaba, eles extraiam essa erva. Saia no sentido de Porto União, era mais longe e aqui quando a estrada de ferro passou a transitar em Cruzeiro do Sul, até um tempo, passou a se chamar Estação Erval motivo que entrava muita erva-mate, naquela estação ali, este Simões Cavalheiro organizou, ele explorava erva e viajava, viajava muito pro Paraguai, Rio Grande do Sul, ele arrumou um comissão de uns vinte paraguaios, naquela época em
1910, então ele contava com os paraguaios que moravam aqui [...] (MARSANGO, 1996).

Essa valorização da erva-mate, bem como o desenvolvimento do setor na região, a partir do início do século XX foi um importante fator de atração de diversas famílias. No entanto, esse mesmo processo iniciou um intenso processo de apropriação privada da terra. A instauração da Lei de Terras em 1850 trouxe uma mudança a respeito da concepção de terras no país. As terras devolutas passaram a ser valorizadas de acordo com as terras privadas, o que dificultava o acesso a terra, seja pelos brasileiros pobres ou pelos imigrantes que aportavam no país desde a segunda década do mesmo século (SABOYA, 1995). Isso os forçava a se tornarem trabalhadores assalariados, afinal, a "disponibilidade de terras e o trabalho livre são, em tese, incompatíveis". Embora a Lei não obtivesse sucesso em seus principais objetivos, a demarcação das terras devolutas e particulares, a transformação da terra em mercadoria teve efeitos profundos no processo de ocupação territorial brasileiro, sobretudo a partir da Primeira República. 
Em Santa Catarina, a política de terras, definida após a Constituição Republicana de 1891, quando as terras devolutas passaram ao domínio dos Estados, baseava-se, nas palavras de Paulo Pinheiro Machado (2004, p. 139),

[...] na premissa segundo a qual Santa Catarina precisava desenvolver sua "indústria pastoril e agricola" e, para isto, já contava com "terras ubérrimas" que eram "desabitadas". Fica evidente a formulação de uma política de terras ligada ao estímulo da colonização européia, voltada para o desenvolvimento de uma lavoura comercial - submetida aos interesses de capital mercantil e de empresas particulares especializadas em especulação com terras [...].

Da mesma forma que em outros estados brasileiros, as populações indígenas estavam completamente alijadas desta política de desenvolvimento. Situação que não era diferente para as famílias caboclas que ocupavam as florestas onde abundavam os ervais. À medida que a erva-mate passava por um processo de mercantilização mais intenso, as terras onde se realizavam tais atividades passavam a ser alvo da apropriação privada, piorando assim a situação do caboclo, que vivia na condição de sitiante independente, pois este teria que, ou se sujeitar as novas condições de trabalho ou partir em busca de novas terras, para reproduzir seu modo de vida costumeiro.

Em relação a isso comenta Maurício Vinhas de Queiroz (1981, p. 64) que "a coleta do mate vinha tendendo a fazer-se cada vez mais e frequente em terras de propriedade privada". Controlados por coronéis, nesse caso uma referência ao "chefe local" (MONTEIRO, 1974), o Estado concedia a estes e seus apaniguados as terras devolutas ricas em ervais. Nesse processo eram frequentes as expulsões violentas de posseiros que antes extraíam a erva-mate de suas posses ou exploravam ervais devolutos em comum.

As terras que não eram alvo de apropriação eram arrendadas pelo Estado aos coronéis, que coibiram a coleta da planta nessas terras pelos moradores locais (QUEIROZ, 1981). Nestes arrendamentos, os prazos de exploração eram variáveis, com o preço do contrato sendo estabelecido em relação a "quantidade de erva-mate extraída, sempre com o cuidado (expresso nas cláusulas de contrato) de exigir que fosse a extração efetuada de modo a conservar os ervais e outras madeiras de qualquer espécie" (CAVALLAZZI, 2003, p. 68). Marli Auras (2001, p. 30) cita o exemplo do Decreto Lei $n^{\circ} 1.273$ de 10 de janeiro de 1891, em que prevê a permissão para a exploração de ervais devolutos por uma empresa ervateira de Joinville pelo prazo de 20 anos em diversos municípios, dentre eles Curitibanos, Campos Novos e Lages.

Em Campos Novos, por exemplo, o jornal Vanguarda (1910, p. 3) publicou no ano de $1910 \mathrm{um}$ edital proibindo a coleta e beneficiamento do mate em terras devolutas que haviam sido concedidas ao Coronel Fabrício Vieira, da mesma maneira que inibiu a coleta de outras plantas ou estabelecimento de roças nas mesmas. O próprio Estado, ao adotar algumas medidas regulatórias para a extração do mate, mencionou o caso das concessões de ervais nativos a particulares conforme se observa n o Art. $1^{\circ}$ Lei Estadual n ${ }^{\circ} 700$, de 27 de outubro de 1906, que dá "providência sobre a herva matte"

\section{Art. $1^{\circ}$ : Nas terras de dominio do Estado que nos termos da Lei forem aforadas a particu- lares, assim como as de dominio municipal e particular, a colheita da herva matte só se fará observadas as seguintes prescripções: \\ a) A poda será feita de $1^{\circ}$ de Maio a 30 de setembro. \\ b) As arvores de matte só poderão ser podadas depois de decorridos tres (3) annos da poda anterior. \\ $\S$ Unico. O infractor incorrerá na multa de $10 \$ 000$ (dez mil-réis) por 15 kilos de herva matte colhida na observancia d'este artigo (SANTA CATARINA, 1906).}

Somou-se a isso a grande quantidade de terras concedidas à Brazil Railway Company, cuja exploração em escala industrial da madeira causava sérios prejuízos aos ervais, uma vez que, ao utilizar grandes guindastes para o arrasto toras de pinheiros e imbuias para serem embarcadas rumo à serraria, destruíam as árvores de erva-mate que encontravam no caminho (AURAS, 2001). 
Para diversas famílias caboclas que viviam sob o regime da posse, em áreas até então marginais à economia pastoril predominante nos campos, essa política foi experimentada como sendo o início da intensificação de um processo de transformações sócio-espaciais relacionadas principalmente à questão da terra. Condição que deu origem a diversas situações de disputa pela sua posse, sendo a Guerra do Contestado, que ocorreu na região entre os anos de 1912 a 1916, o principal marco de resistência da população cabocla (MACHADO, 2004, p. 139).

Nos anos posteriores ao conflito, no entanto, a situação de marginalização da população cabocla se intensificou com a expansão da colonização e a exploração madeireira, tornando mais precário o acesso e a extração da erva-mate pelos caboclos do planalto catarinense.

No Vale do Rio do Peixe e Oeste de Santa Catarina a colonização teve início a partir da década de 1920 com a atuação de várias companhias colonizadoras privadas em terras antes devolutas, colocando "em prática a opção de uma migração dirigida a grupos específicos que se adequassem aos padrões estabelecidos pelo governo estadual e por elas próprias, ou seja, que povoassem e colonizassem a região ordeiramente". A escolha, por parte dos colonizadores, de colonos "ordeiros" e "trabalhadores" não incidiu sobre a população cabocla, mas sim sobre os teutos e ítalo-brasileiros estabelecidos, ao longo do século XIX, nos núcleos de colonização do Rio Grande do Sul (NODARI, 2009, p. 34).

Aos colonizadores interessava a venda daquelas terras. Se para o governo, colonização quer dizer povoamento e desenvolvimento de áreas "desabitadas", para uma companhia particular "quer dizer negócio; ela quer ganhar dinheiro e é certo que ganhará se conseguir uma boa qualidade de terra e também gente de boa qualidade" (WAIBEL, 1949, p. 172). Quando Léo Waibel (1949, p. 174) apresentou o trabalho intitulado Princípios da colonização européia no Sul do Brasil, no final da década de 1940, as terras da região já haviam quase todas sido apropriadas "por indivíduos ou companhias particulares, que especulam sobre a expansão do povoamento em futuro próximo".

A presença da população cabocla, que vivia sob o regime de posse nas terras destinadas à coloni- zação foi desconsiderada pelas autoridades públicas. Moradores que, nas palavras de Mônica Hass (1997, p. 51), "de antigos ocupantes da região passariam por intrusos, já que não se encaixavam com o novo sistema que se instalava", pois sua presença poderia trazer obstáculos à colonização e a comercialização das terras.

Jaci Poli (1995, p. 100), em seu estudo sobre a população cabocla no Oeste catarinense, destaca que a relação entre posseiros e colonizadores era sempre complicada, "principalmente quando envolvia a necessidade de desocupar a posse para dar lugar ao proprietário". Para que a empresa colonizadora pudesse pôr à venda seus lotes, era realizada uma espécie de "limpeza da área", onde o direito de propriedade prevaleceu sobre o direito de posse que, em geral, foi ignorado, visto unicamente como infração ou intrusamento (RENK, 2006, p. 118).

É possível traçar um paralelo da situação apresentada na região a partir da inserção das empresas colonizadoras com o estudo de Octávio Ianni (1981, p. 153) em relação ao município de Conceição do Araguaia na década de 1960 no que cabe ao processo de transformação da terra em mercadoria. De forma semelhante, vislumbrou-se a modificação dos "ritmos e os andamentos, os arranjos e as articulações sociais". Com a colonização as florestas passaram a ser

\section{[...] objeto e meio de produção de valores de troca. [...] Pouco a pouco, ou de súbito, conforme o caso, a terra deixa de ser apenas, ou principalmente objeto e meio de produção de valores de uso. O poder estatal aparece, de forma cada vez mais ostensiva e permanente, como um poder maior destinado a favorecer e acelerar o processo de privatização da terra, nos moldes exigidos pela empresa privada de grande porte (IANNI 1981, p. 154).}

$\mathrm{O}$ avanço desse processo, trazendo em seu bojo novas concepções de uso de um espaço, resultou em um processo de ruptura do antigo modo de vida da população cabocla, transformando a paisagem através da inserção de atividades sócio-econômicas externas, desestruturando antigas concepções de uso e acesso à floresta e recursos naturais, que no caso 
estava também relacionado a produção ervateira. A colonização, carregando consigo uma nova lógica de uso do espaço, baseada na propriedade privada da terra, paulatinamente ia alijando essa população cabocla da terra e dos recursos naturais fundamentais à sua sobrevivência, à medida que avançavam as cercas, as serras e as queimadas.

Se no início observavam-se famílias de colonos também explorando a erva-mate, a tendência com a desvalorização da erva-mate seria a derrubada dos ervais. Essa desvalorização estava também relacionada com presença argentina nas terras brasileiras, que promoveu a coleta de sementes de erva-mate que foram transpostas e cultivadas em território argentino no começo do século XX, tornando a província de Misiones uma das principais produtoras do país a partir da década de 1930 (FERRARI, 2011, p. 147). A produção ervateira em território argentino, juntamente com políticas internas de substituição das importações, promoveu a queda na produção e participação na pauta econômica e catarinense, sendo substituída simultaneamente na região pela atividade madeireira (GOULARTI FILHO, 2012).

A exploração madeireira, concomitante com a conversão de florestas em terras para a agricultura, seria a responsável, conforme Maristela Ferrari (2011, p. 222), pelo desaparecimento de grande parte dos ervais nativos na região Oeste em um prazo de aproximadamente trinta anos. Devastação que seria inclusive promovida pelas próprias ervateiras, que, em um contexto de queda na produção, passaram a comercializar a madeira se aproveitando dos mesmos circuitos já estruturados pelo fluxo da produção ervateira, passando, do lado catarinense, por Dionísio Cerqueira e de lá seguindo à Argentina.

Restou a boa parte desses moradores, excluídos de suas terras, onde poderiam criar seus animais e manter sua roça e do acesso aos ervais, a atividade nas serrarias que aportaram na região, ou o trabalho na coleta da erva-mate, como assalariados contratados pelas indústrias ervateiras que exploravam os ervais restantes na região. A extração da erva-mate era vista pelos colonos e colonizadores como uma atividade inferior, desqualificada, de baixa remuneração, onde o trabalho era, na maioria das vezes, sazonal e itinerante (RENK, 2009). A partir de então, para autores como
Arlene Renk (2006, p. 194), a atividade ervateira passou a constituir um ofício étnico

Aos italianos cabe o espaço da lavoura (pequena propriedade e granja), do comércio e da indústria. Os grupos produtivos envolvidos na erva distribuem-se de modo similar: os donos são italianos; os produtores de erva-mate são colonos ou fazendeiros; $e$ os extratores, invariavelmente, os caboclos. Neste caso, a extração é naturalizada como atividade de caboclos [...]. O corte da erva é "só com eles". "Eles só fazem isso e só sabem fazer isso", afirmam os italianos.

A apropriação privada da terra e a posterior consolidação da colonização, envolvendo o Vale do Rio do Peixe e Oeste, fez com que esse espaço fosse bastante alterado, tanto pela ação das indústrias madeireiras, quanto pela ação dos colonos para a produção de lavouras. Esse processo seria no entendimento das autoridades públicas o responsável por introduzir o "progresso", e o "desenvolvimento" na região (CESCO, 2004, p. 119). Juntamente com a expropriação de suas terras, a população cabocla foi alvo da desqualificação de suas formas de acesso e uso da terra, enquanto foram exaltadas as virtudes dos colonos, principalmente de origem germânica e italiana, em relação a valorização do trabalho e as suas práticas agrícolas.

Marcados pela exclusão, seus descendentes passaram a compor significativa parcela dos moradores da periferia de diversas cidades formadas com o crescimento populacional de diversos núcleos coloniais na região. Sem uma qualificação profissional ou oportunidades de emprego, muitos se encontram desempregados ou buscam sobreviver com trabalhos temporários, compondo também considerável parte dos acampamentos e assentamentos do MST da região (PERTILE, 2013; RENK, 2009).

\section{AGRADECIMENTOS}

Os autores agradecem ao $\mathrm{CNPq}$ pelo auxílio financeiro e a Universidade Federal da Fronteira Sul pela bolsa. 


\section{REFERÊNCIAS}

ABREU, Maurício de Almeida. A apropriação do território no Brasil colonial. In: CASTRO, Iná Elias; GOMES, Paulo César da Costa; CORRÊA, Roberto Lobato (org.). Explorações geográficas: percursos no fim do Século. Rio de Janeiro: Bertrand Brasil, 1997.

AIRES DE CASAL, Manoel de. Corografia brasílica ou relação histórico geográfica do Reino do Brazil. Disponível em: <http://www.dominiopublico.gov. br/download/texto/me003003.pdf > . Acesso em: 5 maio. 2010.

ANDRADE, Fabiana Maia. Exploração, manejo e potencial socioeconômico da erva-mate. In: SIMÕES, Luciana Lopes; LINO, Clayton Ferreira. Sustentável Mata Atlântica: a exploração de seus recursos florestais. 2. ed. São Paulo: SENAC, 2003

AURAS, Marli. Guerra do Contestado: a organização da irmandade cabocla. 4. ed. Florianópolis: Ed. da UFSC, 2001.

BRANDT, Marlon; NODARI, Eunice Sueli. Comunidades tradicionais da Floresta de Araucária de Santa Catarina: territorialidade e memória. História Unisinos. São Leopoldo, v. 15, n. 1, p. 80-90, 2011. DOI: http://dx.doi.org/10.4013/htu.2011.151.09

BRANDT, Marlon. Uma história ambiental dos Campos do Planalto de Santa Catarina. 2012, $332 \mathrm{f}$. Tese (Doutorado em História) - Centro de Filosofia e Ciências Humanas, Universidade Federal de Santa Catarina, Florianópolis, 2012.

CAVALLAZZI, Rosângela Lunardelli. Contestado: tempo do camponês, espaço da propriedade privada. Florianópolis: Fundação Boiteux, 2003.

CESCO, Susana. Desmatamento e Migração no Alto Vale do Rio o Peixe: discussões sobre o "progresso" e transformação ambiental. 2004, 135 f. Dissertação (Mestrado em História) - Centro de Filosofia e Ciências Humanas, Universidade Federal de Santa Catarina, Florianópolis, 2004.
CLAVAL, Paul. A paisagem dos geógrafos. In: CORREAA, Roberto Lobato; ROSENDAHL, Zeny (org.). Paisagens textos e identidade. Rio de Janeiro: Ed. da UERJ, 2004.

CORRÊA, Roberto Lobato. O sudoeste paranaense antes da colonização. Revista Brasileira de Geografia. Rio de Janeiro, n. 1, ano 32, p. 87-98, 1970.

COSTA, Emília Viotti da. Política de terras no Brasil e nos Estados Unidos. Da Monarquia à República: momentos decisivos. 7. ed. São Paulo: Ed. da UNESP, 1999.

FERRARI, Maristela. Interações transfronteiriças na zona de fronteira Brasil-Argentina: o Extremo-Oeste de Santa Catarina e Paraná e Província de Misiones (Século XX e XIX). 2011. 445 f. Tese (Doutorado em Geografia) - Centro de Filosofia e Ciências Humanas, Universidade Federal de Santa Catarina, 2011.

GERHARDT, Marcos. História Ambiental da erva-mate. 2013. 290 f. Tese (Doutorado em História). Centro de Filosofia e Ciências Humanas, Universidade Federal de Santa Catarina, Florianópolis, 2013.

GOULARTI FILHO, Alcides. Complexo ervateiro e a pequena produção mercantil em Santa Catarina. Diálogos. Maringá, v. 16, n. 1, p. 179-215, jan./abr. 2012.

HASS, Monica. Os partidos políticos e a elite chapecoense: um estudo de poder local - 1945 a 1965. Chapecó: Grifos, 1997.

IANNI, Octávio. A luta pela terra: história social da terra e da luta pela terra numa área da amazônia. 3. ed. Petrópolis: Vozes, 1981. (Coleção Sociologia Brasileira, V. 3).

MACHADO, Paulo Pinheiro. Lideranças do Contestado: a formação e a atuação das chefias caboclas (1912-1916). Campinas: Unicamp, 2004.

MARSANGO, Davi. Entrevista realizada com Davi Marsango. Ponte Serrada, Santa Catarina, em 15 de novembro de 1996. Acervo do Centro de Memória do 
Oeste de Santa Catarina (CEOM), Chapecó, 1996.

MONTEIRO, Duglas Teixeira. Errantes do novo século. São Paulo: Duas Cidades, 1974.

O CRUZEIRO. Cruzeiro do Sul (Joaçaba): ano 1, n. 8, 7 de janeiro de 1934, p. 5 .

PARANÁ, Sebastião. Chorographia do Paraná. Curitiba: Typ. Da Livraria Econômica, 1899.

PERTILE, Noeli. Espacialidade das ações humanas: o trabalho cotidiano na agricultura familiar do Oeste catarinense. In: CAMPOS, Nazareno José de; BRANDT, Marlon; CANCELIER, Janete Webler. O espaço rural de Santa Catarina: novos estudos. Florianópolis: Ed. da UFSC, 2013.

PHILO, Chris. História, geografia e o "mistério ainda maior" da geografia histórica. In: GREGORY, Derek, MARTIN, Ron, SMITH, Graham (org.). Geografia humana: sociedade, espaço e ciência social. Rio de Janeiro: Zahar, 1996.

POLI, Jaci. Caboclo: pioneirismo e marginalização. In: CENTRO DE ORGANIZAÇÃO DA MEMÓRIA SÓCIO-CULTURAL DO OESTE (org.). Para uma história do Oeste catarinense: 10 anos do CEOM. Chapecó: UNOESC, 1995.

QUEIROZ, Maurício Vinhas de. Messianismo e conflito social: a guerra sertaneja do Contestado (1912-1916). 3. ed. São Paulo: Ática, 1981. (Coleção Ensaios, n. 23).

RENK, Arlene. A luta da erva: um ofício étnico no Oeste catarinense. 2. ed. Chapecó: Argos, 2006.

RENK, Arlene. Expropriação do campesinato do Oeste catarinense. In: GODOI, Emília Pietrafesa de; MENEZES, Marilda Aparecida de; MARIN, Rosa Acevedo (orgs.). Diversidade do campesinato: expressões e categorias: construções identitárias e sociabilidades. Vol. 1. São Paulo: Ed. da UNESP; Brasília: Núcleo de Estudos Agrários e Desenvolvimento Rural, 2009.
SABOYA, Vilma Elisa Trindade de. A Lei de Terras (1850) e a Política Imperial - seus reflexos na Província de Mato Grosso. Revista Brasileira de História. São Paulo, v. 15, n. 30, p. 115-136, 1995.

SAINT-HILLAIRE, Auguste. Viagem a Curitiba e Província de Santa Catarina. Belo Horizonte: Itatiaia/ São Paulo: Ed. da USP, 1978.

SANTA CATARINA. Lei $\mathrm{n}^{\circ} 700$, de 27 de outubro de 1906. Colecção de Leis do Estado de Santa Catharina. Florianópolis: Gab. Typographico d'O Dia, 1906, p. 15-16.

SILVA, Rita Fernandes da. Entrevista realizada com Rita Fernandes da Silva. Chapecó, Santa Catarina em 30 de janeiro de 2006. Acervo do Centro de Memória do Oeste de Santa Catarina (CEOM). Chapecó, 20066.

VANGUARDA. Campos Novos. Ano 4, n. 4, $1^{\circ}$ de junho, 1910.

WAIBEL, Léo. Princípios da colonização européia no Sul do Brasil. Revista Brasileira de Geografia. Rio de Janeiro, n. 2, ano 12, p. 159-222, abr./jun. 1949. 